\title{
The Aeolus project: Science outreach through art
}

1. Ian A. Drumm1

2. Amanda Belantara1

3. Steve Dorney2

4. Timothy P. Waters2

5. Eulalia Peris1

1. 'University of Salford, UK

2. ${ }^{2}$ University of Southampton, UK

1. Ian A. Drumm, Acoustics Research Centre, The University of Salford, Manchester M5 4WT, UK.

Email: i.drumm@salford.ac.uk

\begin{abstract}
With a general decline in people's choosing to pursue science and engineering degrees there has never been a greater need to raise the awareness of lesser known fields such as acoustics. Given this context, a large-scale public engagement project, the 'Aeolus project', was created to raise awareness of acoustics science through a major collaboration between an acclaimed artist and acoustics researchers. It centred on touring the large singing sculpture Aeolus during 2011/12, though the project also included an extensive outreach programme of talks, exhibitions, community workshops and resources for schools. Described here are the motivations behind the project and the artwork itself, the ways in which scientists and an artist collaborated, and the public engagement activities designed as part of the project. Evaluation results suggest that the project achieved its goal of inspiring interest in the discipline of acoustics through the exploration of an otherworldly work of art.
\end{abstract}

